\title{
Natural and long-lasting cellular immune responses against influenza in the M2e-immune host
}

\author{
M Schotsaert ${ }^{1,2}$, T Ysenbaert ${ }^{1,2}$, K Neyt $^{1,2}$, LI Ibañez $^{1,2}$, P Bogaert $^{1,2}$, B Schepens ${ }^{1,2}$, BN Lambrecht $^{1,2}$, \\ $\mathrm{W}$ Fiers $^{1,2}$ and $\mathrm{X}$ Saelens ${ }^{1,2}$
}

Influenza is a global health concern. Licensed influenza vaccines induce strain-specific virus-neutralizing antibodies but hamper the induction of possibly cross-protective T-cell responses upon subsequent infection. ${ }^{1}$ In this study, we compared protection induced by a vaccine based on the conserved extracellular domain of matrix 2 protein (M2e) with that of a conventional whole inactivated virus (WIV) vaccine using single as well as consecutive homo- and heterosubtypic challenges. Both vaccines protected against a primary homologous (with respect to hemagglutinin and neuraminidase in WIV) challenge. Functional T-cell responses were induced after primary challenge of M2e-immune mice but were absent in WIV-vaccinated mice. M2e-immune mice displayed limited inducible bronchus-associated lymphoid tissue, which was absent in WIV-immune animals. Importantly, M2e- but not WIV-immune mice were protected from a primary as well as a secondary, severe heterosubtypic challenge, including challenge with pandemic $\mathrm{H} 1 \mathrm{~N} 1$ 2009 virus. Our findings advocate the use of infection-permissive influenza vaccines, such as those based on M2e, in immunologically naive individuals. The combined immune response induced by M2e-vaccine and by clinically controlled influenza virus replication results in strong and broad protection against pandemic influenza. We conclude that the challenge of the M2e-immune host induces strong and broadly reactive immunity against influenza virus infection.

\section{INTRODUCTION}

Human influenza viruses infect epithelial cells at the mucosal sites of the upper and lower airways. Seasonal influenza causes up to half a million deaths annually and severe morbidity in three to five million people. ${ }^{2}$ Pandemic outbreaks like the one caused by the 2009 pandemic H1N1 virus (pH1N1) occur less frequently and are typically associated with extensive mortality. ${ }^{3}$ Currently, licensed vaccines mainly induce strain-specific neutralizing antibodies against hemagglutinin (HA), the main antigenic determinant on the surface of the virion, and can prevent disease caused by infection with a matching virus strain. However, antigenic drift of HA allows influenza viruses to evade antibody-mediated neutralization and necessitates yearly updates of licensed vaccines. The strain specificity of current vaccines may result in vaccine ineffectiveness when circulating viruses do not match circulating strains, e.g., in case of a pandemic.

Natural infection with influenza A virus induces humoral and cellular immunity. Long-lasting cellular immunity is directed predominantly against conserved, internal viral proteins, such as nucleoprotein (NP). ${ }^{4} \mathrm{CD} 8{ }^{+} \mathrm{T}$-cell responses are essential for virus clearance and provide heterosubtypic immunity (HSI). ${ }^{5,6}$ This cellular HSI is, however, blunted in individuals who have been vaccinated with conventional vaccines upon exposure to homotypic virus. ${ }^{1,7-9}$ Therefore, there is worry that yearly vaccination of young children with seasonal influenza vaccines could compromise the induction and maturation of primary cellular responses against influenza virus. ${ }^{10}$ Many Western countries are now implementing full seasonal influenza vaccination coverage from early childhood on. ${ }^{11}$ Hence, this policy may result in a growing cohort of individuals with negligible cellular HSI.

Here, we propose a solution for this risk: an infection-permissive vaccine that is based on the relatively conserved extracellular domain of matrix 2 protein (M2e) antigen. ${ }^{12,13}$ Immunization with recombinant virus-like particles (VLP) that present M2e induces cross-protective serum-transferable immunity against influenza A. ${ }^{12}$ Here we compared immunity induced by M2e-VLP

\footnotetext{
${ }^{1}$ Department for Molecular Biomedical Research, VIB, Ghent, Belgium. ²Department of Biomedical Molecular Biology, Ghent University, Ghent, Belgium. Correspondence: X Saelens (xavier.saelens@dmbr.vib-ugent.be) 
with that induced by a conventional influenza vaccine. We assessed protection against both primary and secondary influenza virus challenge and determined cellular immune response and inducible bronchus-associated lymphoid tissue (iBALT) formation. We used a model that mimics primary exposure to seasonal influenza followed by a secondary, more severe heterosubtypic influenza virus infection, the latter mimicking a pandemic outbreak. We found that, unlike mice that had been immunized with whole inactivated virus (WIV), challenged M2e-immune mice mount a robust cellular immune response against influenza A virus antigens, in the absence of overt disease.

\section{RESULTS}

M2e-immune mice are protected against influenza $A$ virus infection without affecting cross-reactive effector CD8 + T-cell responses

We first demonstrated that mice immunized with M2e-VLP were protected against a potentially lethal challenge with $\mathrm{NC}$ (A/New Caledonia/20/99) virus, a challenge virus that we had not used before in our mouse model (Figure 1). We also quantified and characterized NP- and HA-specific $\mathrm{CD} 8{ }^{+} \mathrm{T}$-cell responses in M2e-immune mice 3 weeks after infection with a sublethal dose of NC virus. Remarkably, following primary challenge, NP- and HA-specific CD8 ${ }^{+}$T-cell numbers were similar and in some experiments even higher in the M2e-VLP-vaccinated group than in controls as determined by enzyme-linked immunospot and intracellular cytokine staining (ICS; Figure 2). This indicates that M2e-VLP vaccination protects against influenza without affecting $\mathrm{CD} 8{ }^{+} \mathrm{T}$-cell responses directed against influenza antigens.

\section{Vaccine antigens and recurrent infection model}

We used pairs of mouse-adapted influenza A viruses for successive challenges. Primary infection was with a sublethal but disease-provoking dose of a virus of a given subtype (H3N2 or H1N1). The secondary challenge was with a potentially lethal dose (i.e., lethal for control animals) of a virus with a different subtype (H1N1 or $\mathrm{H} 3 \mathrm{~N} 3$ ) compared with the primary challenge virus (Figure 3a). In this model, the primary, sublethal infection with mouse-adapted NC (H1N1; group $1 \mathrm{HA}$ and neuraminidase (NA)) or X47 (H3N2) virus (group $2 \mathrm{HA}$ and NA) mimics exposure to "seasonal" influenza virus. Four weeks after primary infection, when mice were fully recovered, the animals were challenged with a second, potentially lethal dose of mouseadapted H3N3 (A/swine/Ontario/42729A/01; group $2 \mathrm{HA}$ and $\mathrm{NA}$ ) or pH1N1 virus (group $1 \mathrm{HA}$ and NA), respectively. The viruses used for subsequent challenges thus had HAs and NAs belonging to different phylogenetic groups (Figure 3b). This second, heterosubtypic, and more lethal infection represents a pandemic challenge. WIV vaccines corresponding to the primary strains ( $\mathrm{NC}$ or X47) were produced by formalin inactivation of the corresponding, purified virions, and M2e-VLP displaying a human-type M2e consensus sequence were prepared as described previously,14 (Figure 3c). To control for the effect of the primary infection on the outcome of the secondary challenge,
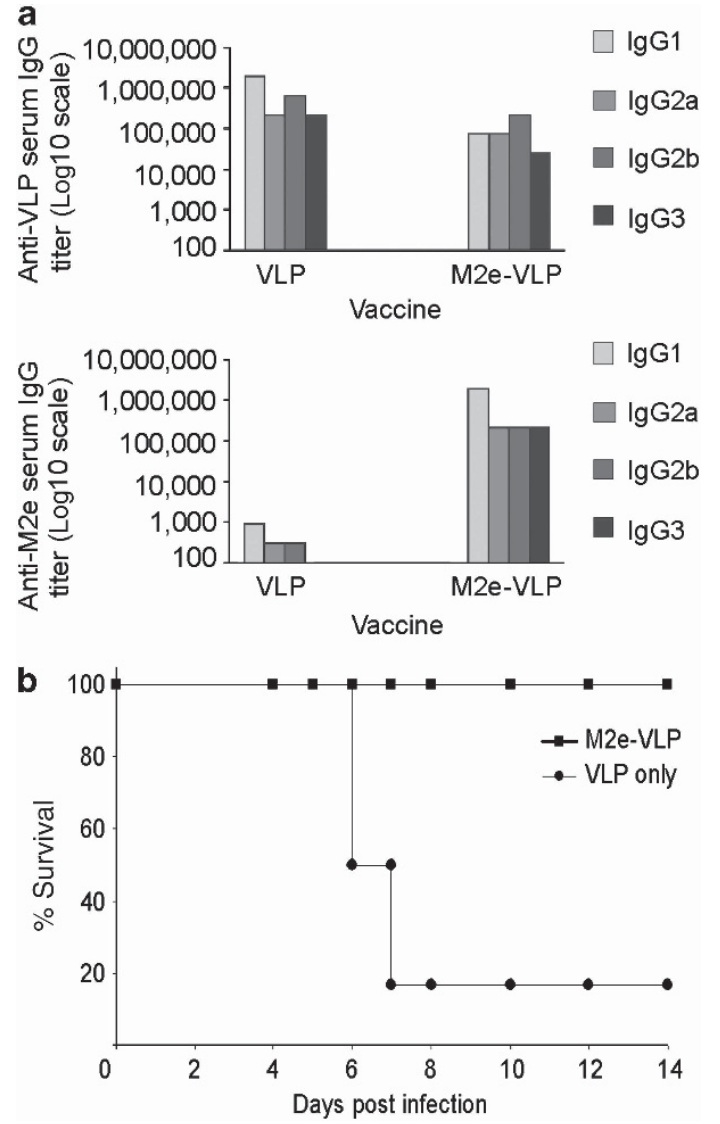

Figure 1 Extracellular domain of matrix 2 protein (M2e)-immunized mice are protected against challenge with mouse-adapted $\mathrm{A} / \mathrm{New}$ Caledonia/20/99 (NC) virus. BALB/c mice (six per group) were immunized by intraperitoneal injection with $5 \mu \mathrm{g}$ M2e-VLP (virus-like particles) or VLP, adjuvanted with incomplete Freund's adjuvant. (a) Seroconversion status of M2e-VLP or VLP-vaccinated mice before challenge. Endpoint titers in serum pool from each group for the indicated immunoglobulin $\mathrm{G}(\mathrm{lgG})$ isotypes directed against hepatitis $\mathrm{B}$ core antigen (upper graph; VLP) and M2e (lower graph). (b) Six weeks after the last vaccination, mice were challenged intranasally with $8 L_{50}$ (lethal dose, $50 \%$ ) of mouse-adapted NC virus. Mortality rates were monitored for 2 weeks after challenge.

control-vaccinated (phosphate-buffered saline (PBS) and unsubstituted carrier VLP) mice were included. In addition, the efficacy of WIV and M2e-VLP immunization was determined by including groups of mock-challenged mice at the time of primary challenge (Figure 3a).

We compared the protective efficacy of vaccination with M2e-VLP with that of WIV against primary homologous (with respect to HA and NA antigens for WIV) followed by a secondary heterologous and more severe challenge (Figure 3a). Two entirely independent experiments were performed. We focus on the experiment in which X47 (H3N2) virus was used for primary challenge followed by challenge with the $2009 \mathrm{pH} 1 \mathrm{~N} 1$ virus because this setting mimics the winter season in the northern hemisphere during which $\mathrm{H} 3 \mathrm{~N} 2$ viruses predominated and which was followed by the pandemic $\mathrm{pH} 1 \mathrm{~N} 1$ outbreak. Immunization with WIV prepared from X47 and NC virions 

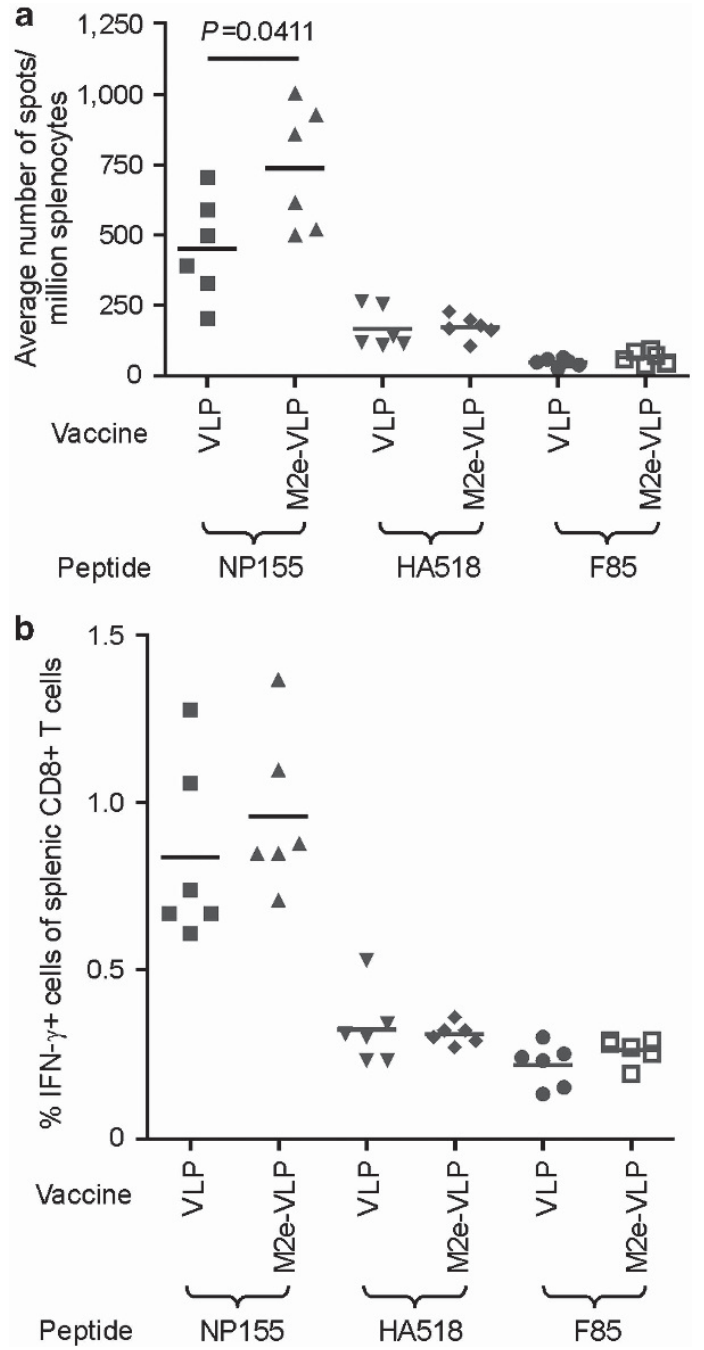

Figure 2 Extracellular domain of matrix 2 protein (M2e)-immune mice mount Influenza A virus-specific CD8 ${ }^{+}$T-cell responses after challenge. Mice (six per group) were immunized three times with 3-week intervals by intraperitoneal injection with $5 \mu \mathrm{g}$ M2e-VLP (virus-like particles) or unsubstituted VLP adjuvanted with incomplete Freund's adjuvant. Four weeks after the last immunization, the animals were challenged with 0.1 $\mathrm{LD}_{50}$ (lethal dose, 50\%) NC (A/New Caledonia/20/99) virus. Twenty days after challenge, splenocytes were prepared and restimulated ex vivo for $16 \mathrm{~h}$ with the indicated peptides. (a) Interferon (IFN)- $\gamma$ enzyme-linked immunospot analysis of restimulated splenocytes. Statistical significance ( $P$ value) was calculated using a two-sided Mann-Whitney $U$ test. (b) Flow cytometric analysis of IFN- $\gamma$-producing $\mathrm{CD}^{+}{ }^{+} \mathrm{T}$ cells after ex vivo restimulation of splenocytes. HA, hemagglutinin; NP, nucleoprotein.

induced strong neutralizing antibody titers, and also M2e-VLP immunized mice seroconverted as expected (Figure $\mathbf{4 a}, \mathbf{b}$ and see Supplementary Figure S1a-d online). Compared with controls, both WIV- and M2e-immune animals were significantly protected from severe weight loss upon primary, antigenically homologous challenge (Figure 5a and see Supplementary Figure S2a online). Virus titers in the lungs were below detection limit in the X47-WIV group and were more than tenfold lower in M2e-VLP immunized mice than in controls (Figure 5b and see Supplementary Figure S2b online).

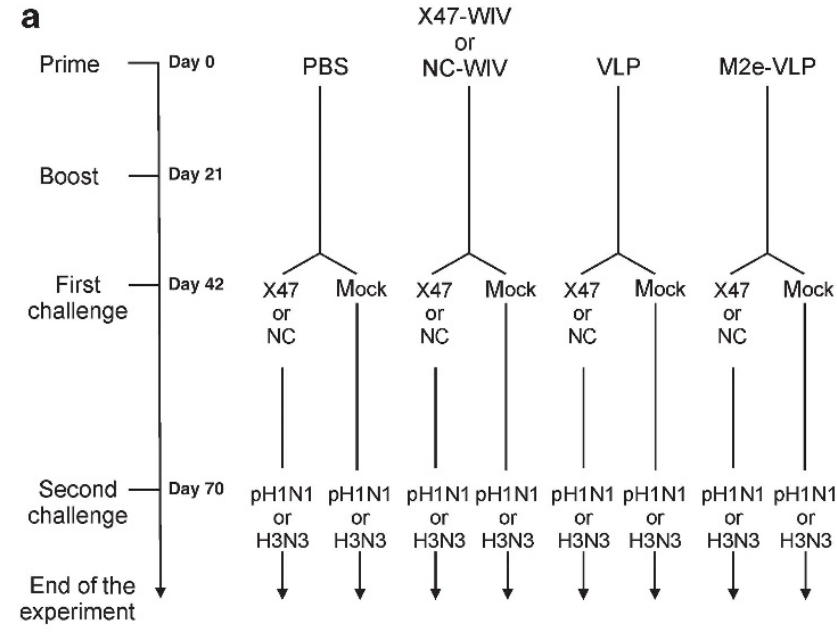

b
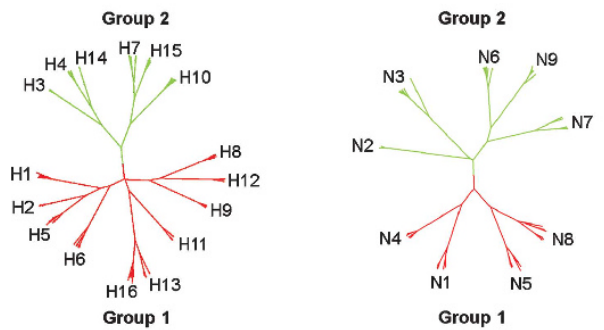

c

$\begin{array}{ll}\text { Consensus sequence: } & \text { SLLTEVETPIRNEWGCRCNDSSD } \\ \text { X47 } & \text { SLLTEVETPIRNEWGCRCNGSSD } \\ \text { pH1N1 } & \text { SLLTEVETPTRSEWECRCSDSSD } \\ \text { A/New Caledonia/20/99: } & \text { SLLTEVETPIRNEWGCRCNDSSD } \\ \text { A/Swine/Ontario/42729A/01: } & \text { SLLTEVETPTRNGWECRCSDSSD }\end{array}$

Figure 3 Experimental model and choice of vaccines and viruses. (a) On the left is the time schedule of primer and booster vaccinations as well as the two subsequent viral challenges. Four groups of mice were compared in two independent experiments. In the first experiment (59-63 mice per group), primary challenge was with X47 (H3N2, 0.2 $\mathrm{LD}_{50}$ (lethal dose, $\left.50 \%\right)$ ) and the second challenge with pandemic $\mathrm{H} 1 \mathrm{~N} 1$ ( $\mathrm{pH} 1 \mathrm{~N} 1)$ virus $\left(2 \mathrm{LD}_{50}\right)$. In the second experiment (59-63 mice per group), the first challenge was with $\mathrm{A} / \mathrm{New}$ Caledonia/20/99 (NC, H1N1, $\left.0.1 \mathrm{LD}_{50}\right)$ and the second challenge with $\mathrm{A} /$ swine/Ontario/42729A/01 virus $\left(\mathrm{H} 3 \mathrm{~N} 3,2 \mathrm{LD}_{50}\right)$. Half of the mice in each group were exposed to the first challenge (experiment 1: X47; experiment 2: $\mathrm{NC}$ ) and the other half was mock-challenged. All remaining animals were exposed to the second challenge on day 70 (experiment 1: $\mathrm{pH} 1 \mathrm{~N} 1$; experiment 2: H3N3). (b) Phylogenetic tree with the 16 known hemagglutinin (HA; left) and the 9 known neuraminidase (NA; right) subtypes. The tree was created with Dendrograph version 2.7.4. using the 10 earliest $\mathrm{HA}$ and NA entries in the influenza database for each subtype as input. (c) Comparison of extracellular domain of matrix 2 protein (M2e) amino-acid residue sequences. The top line represents the human consensus sequence as present in the M2e-VLP (virus-like particles) vaccine used. Amino-acid residues in $\mathrm{M} 2 \mathrm{e}$ of the challenge viruses that differ from $\mathrm{M} 2 \mathrm{e}$ in the M2e-VLP vaccine are highlighted in bold. PBS, phosphate-buffered saline; WIV, whole inactivated virus.

\section{M2e-immune but not WIV-immune hosts mount functional $\mathrm{CD}^{+}{ }^{+} \mathrm{T}$-cell responses upon viral challenge}

Antigen-dependent $\mathrm{CD} 4^{+}$and $\mathrm{CD} 8^{+} \mathrm{T}$-cell responses were analyzed in splenocytes, isolated 10 days after primary infection. NP155-specific $\mathrm{CD}^{+}{ }^{+} \mathrm{T}$-cell levels were similar in control and M2e-VLP-vaccinated groups but significantly lower in WIV-immunized animals after challenge (Figure $\mathbf{5 c}$ and 

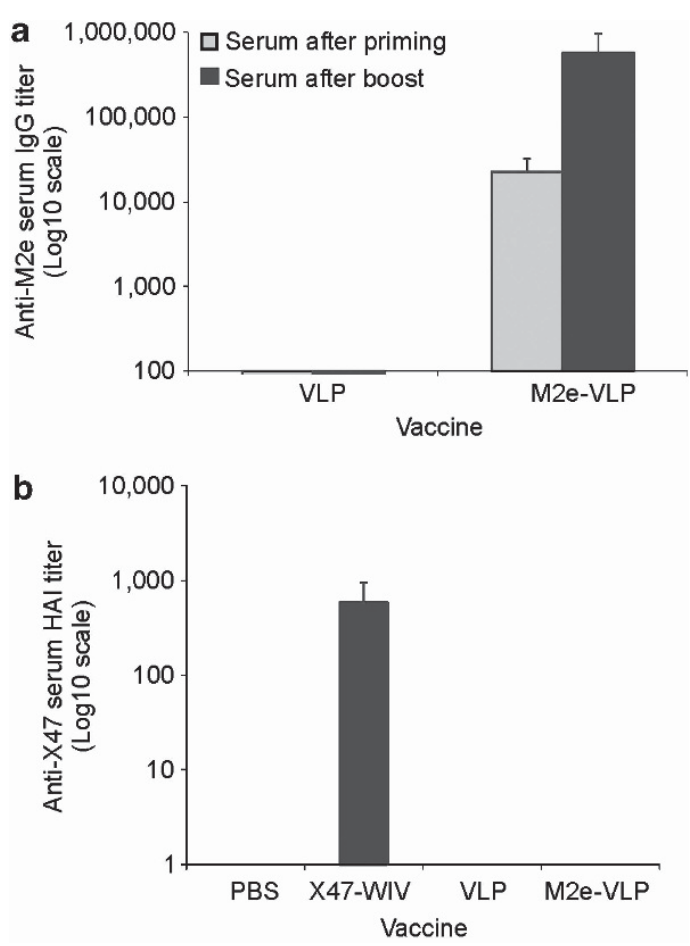

Figure 4 Seroconversion after prime/boost vaccination with extracellular domain of matrix 2 protein (M2e)-VLP (virus-like particles) and X47-WIV (whole inactivated virus). (a) Endpoint M2e-specific serum immunoglobulin $\mathrm{G}(\mathrm{IgG})$ titers in VLP and M2e-VLP-immunized BALB/c mice. (b) Hemagglutination inhibitory (HAI) antibodies in serum after boost vaccination with the indicated antigens. HAI endpoint titers were determined using chicken red blood cells and four hemagglutinin units of X47 virus. Bars represent averages ( $n=20$ per group) and error bars represent standard deviations. PBS, phosphate-buffered saline.

see Supplementary Figure S2c,d online). We also determined interferon (IFN) $-\gamma$ production by pentamer-positive splenic $\mathrm{CD}^{+} \mathrm{T}$ cells after ex vivo stimulation with the HA518 peptide that is subdominant to the NP155 CTL (cytotoxic T-lymphocyte) epitope. ${ }^{15}$ The dominance of NP- over HAspecific $\mathrm{CD} 8{ }^{+} \mathrm{T}$-cell responses was comparable in challenged control and M2e-VLP mice (see Supplementary Figure S2c,d online). Using a functional in vivo killing assay, we showed that M2e-VLP-vaccinated mice, but not WIV-vaccinated animals, specifically cleared NP155-pulsed target cells almost as efficiently as challenged PBS- or VLP-immunized mice (Figure 5d and see Supplementary Figure S2e online). Vaccination with M2e-VLP as well as infection with NC also results in the induction of an $\mathrm{H} 2 \mathrm{~d}$-restricted M2e-specific T-helper type 1 response (see Supplementary Figure S2f online).

Protection against influenza correlates with the level of virusneutralizing antibodies in serum. X47 and NC challenge induced very low M2e-specific serum immunoglobulin $G(\operatorname{IgG})$ titers in control-vaccinated groups, confirming the poor immunogenicity of native M2e. ${ }^{16}$ However, mock-challenged WIV-immunized animals and all challenged mice had strong homologous serum hemagglutination inhibition (HAI) titers (Figure $\mathbf{6}$ and see Supplementary Figure S3 online).
iBALT in response to viral challenge is higher in M2e-VLPcompared with WIV-immune mice, and reduced compared with control mice

Respiratory infection of human and mouse can induce iBALT formation, which has been associated with enhanced protection against influenza $\mathrm{A}$ virus challenge in mice. ${ }^{17}$ We analyzed iBALT formation on day 21 after primary infection, when mice were fully recovered. Germinal center formation was evaluated by flow cytometry to count GL7-expressing $\mathrm{IgM}^{-} / \mathrm{IgD}^{-} \mathrm{B}$ cells, and we confirmed the results by immunohistochemistry. iBALT formation was evident in PBS- and VLP-immunized mice, but not in WIV-immune mice that had been exposed to influenza virus (Figure 7 and see Supplementary Figure S4 online). Interestingly, following primary infection of M2e-immune mice, the extent of iBALT induction was significantly higher than in X47-WIV-vaccinated mice but lower than in control mice (Figure 7b). We conclude that M2e immunity reduces but does not prevent iBALT formation following influenza A virus challenge.

\section{Previous infection contributes to protection by M2e-VLP vaccination against heterosubtypic challenge}

Mice that had fully recovered from the primary infection as well as all mice that had previously been mock-infected, were challenged with a severe dose of a heterosubtypic virus. Despite the incomplete match between the M2e sequences in M2e-VLP and these "pandemic" challenge viruses, previously mockchallenged M2e-immune animals survived pH1N1 and H3N3 challenges although morbidity was pronounced. By contrast, most of the control and WIV-immunized animals died after infection (Figure 8a,c and see Supplementary Figure S5a,c online). In line with recent findings, we observed that previous infection of naive mice with $\mathrm{X} 47$, was associated with robust protection against $\mathrm{pH} 1 \mathrm{~N} 1$ challenge. ${ }^{18}$ In mice that had been pre-exposed to "seasonal" X47 or NC virus, protection from morbidity and lethality was significantly stronger in the PBS, VLP, or M2e-VLP than in the WIV groups (Figure 8b,d and see Supplementary Figure S5b,d online). In addition, M2eVLP-immunized mice displayed the lowest "pandemic" lung virus load of all corresponding similarly challenged groups, except for the PBS control mice that had been pre-exposed to X47 challenge. By contrast, "pandemic" lung virus loads in WIV-immune mice were equal to (for the previously mockchallenged groups) or even higher (for the previously X47or NC-challenged groups) than those in all the other groups (Figure 9a and see Supplementary Figure S6a online).

\section{Reinfection boosts CD8 ${ }^{+} \mathrm{T}$-cell responses in M2e-immune mice}

The $\mathrm{H}_{2}{ }^{\mathrm{d}}$-restricted NP155 CTL epitope is conserved in the challenge viruses we used. Therefore, we also analyzed whether reinfection boosts NP-specific CD8 ${ }^{+} \mathrm{T}$ cells by using peptidespecific in vivo ICS. Compared with M2e-immune mice that had survived primary challenge with $\mathrm{pH} 1 \mathrm{~N} 1$ or $\mathrm{H} 3 \mathrm{~N} 3$ virus, these T-cell responses were significantly higher in consecutively challenged M2e-VLP-immune mice and comparable with the 

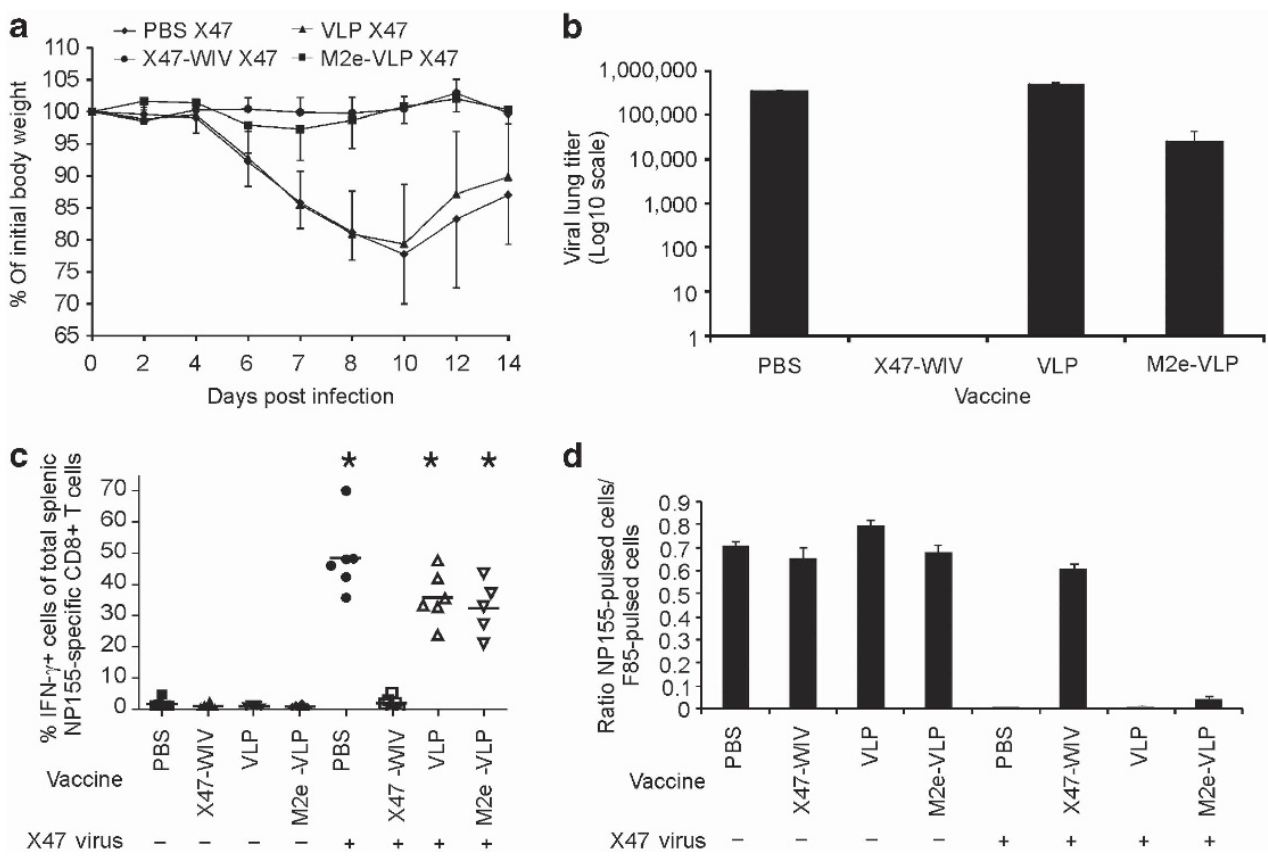

Figure 5 Immune protection, viral lung titers, and ex vivo-restimulated T-cell responses after primary challenge. (a) Mice (12 per group) immunized with phosphate-buffered saline (PBS), X47-WIV (whole inactivated virus), virus-like particles (VLP) or extracellular domain of matrix 2 protein (M2e)VLP, as indicated, were challenged with 0.2 LD $_{50}$ (lethal dose, $50 \%$ ) of mouse-adapted X47 virus and body weight was recorded daily. Differences in body weight between groups vaccinated with X47-WIV and M2e-VLP are significant on the second day post infection (dpi; two-sided Mann-Whitney $U$ test, $P<0.05)$. Mice mock-vaccinated with PBS- or VLP control showed significantly more morbidity than mice vaccinated with X47-WIV or M2e-VLP between 6 and 14 dpi (two-sided Mann-Whitney $U$ test $P<0.05$ ). (b) Lung virus titers were determined by endpoint titration on MDCK (Madin-Darby canine kidney) cells in cleared lung homogenates harvested on day 6 after infection. (c) Interferon (IFN)- $\gamma$ production in splenic nucleoprotein (NP)specific $\mathrm{CD}^{+} \mathrm{T}$ cells as determined by NP155 pentamer staining and flow cytometric analysis of splenocytes isolated on day 10 after primary challenge with X47 virus. ( ${ }^{\star} P<0.01$ for PBS, VLP, and M2e-VLP compared with X47-WIV group by two-sided Mann-Whitney U test). (d) T-cell responses in challenged control and M2e-VLP-vaccinated mice but not in X47-WIV-vaccinated mice can kill NP155-pulsed target cells in vivo. Bars represent the ratio between the number of NP155-pulsed target cells and the number of control F85-pulsed target cells that were recovered from spleens of mice that received the indicated treatment. Error bars represent standard deviations.

T-cell responses in consecutively challenged PBS- and VLPimmunized mice (Figure $\mathbf{9 b}$ and see Supplementary Figure S6b online). By contrast, NP155-specific T-cell responses in X47WIV-immune mice that had survived the secondary infection were comparable with those detected in M2e-VLP mice that had been challenged only once (Figure $9 \mathbf{b}$ and see Supplementary Figure S6b online).

\section{DISCUSSION}

We report that M2e-based vaccination protects mice against challenges with different influenza A virus subtypes ( $\mathrm{H} 1 \mathrm{~N} 1$, $\mathrm{H} 3 \mathrm{~N} 2$, and $\mathrm{H} 3 \mathrm{~N} 3$ ), and does so without affecting the induction of an adaptive immune response against the challenge virus. Virus-neutralizing and cross-reactive effector $\mathrm{CD}^{+}$ $\mathrm{T}$-cell responses in M2e-immune mice were comparable with those observed in control mice with the notable difference that the latter mice suffered from significant disease upon primary virus challenge, whereas M2e-immune animals displayed little, if any, weight loss upon a primary sublethal challenge. By sharp contrast, vaccination with WIV, a conventional type of influenza vaccine, fails to protect against challenge with heterosubtypic viruses and abrogates the induction of (cross-reactive) $\mathrm{T}$-cell responses upon challenge with a homologous virus. The latter observation is in line with the recently published data. ${ }^{7}$ As a consequence, although WIV vaccination can efficiently protect against homologous challenges, it fails to protect against a subsequent challenge with heterosubtypic virus. By contrast, the protection of M2e-vaccinated mice against a secondary, heterosubtypic, and more severe challenge is mediated by both vaccination and adaptive cellular immune responses induced by a primary influenza A virus experience.

The quest for a universal vaccine that protects against multiple influenza subtypes is driven by the fear that a new pandemic virus will emerge from the animal reservoir. Such a vaccine should be based on antigenic determinants that are shared by all virus subtypes such as M2e. M2e-based immunity lasts for at least 6 months in the mouse model, relies on anti-M2e IgG, $\mathrm{Fc} \gamma$ receptors, alveolar macrophages, and dendritic cells. ${ }^{12,19-21}$ In contrast to HA-specific neutralizing antibodies that are the prime effectors of licensed influenza vaccines, M2e-based antiviral immunity is not sterilizing. Therefore, in experimental head-to-head comparison with a conventional vaccine and strain-matched challenge virus, immunity induced by M2e vaccine is considered weaker ${ }^{22,23}$ even though immunization with some M2e-fusion constructs protected mice against challenge doses as high as $150 \mathrm{LD}_{50}$ (lethal dose, 50\%). ${ }^{24}$ 

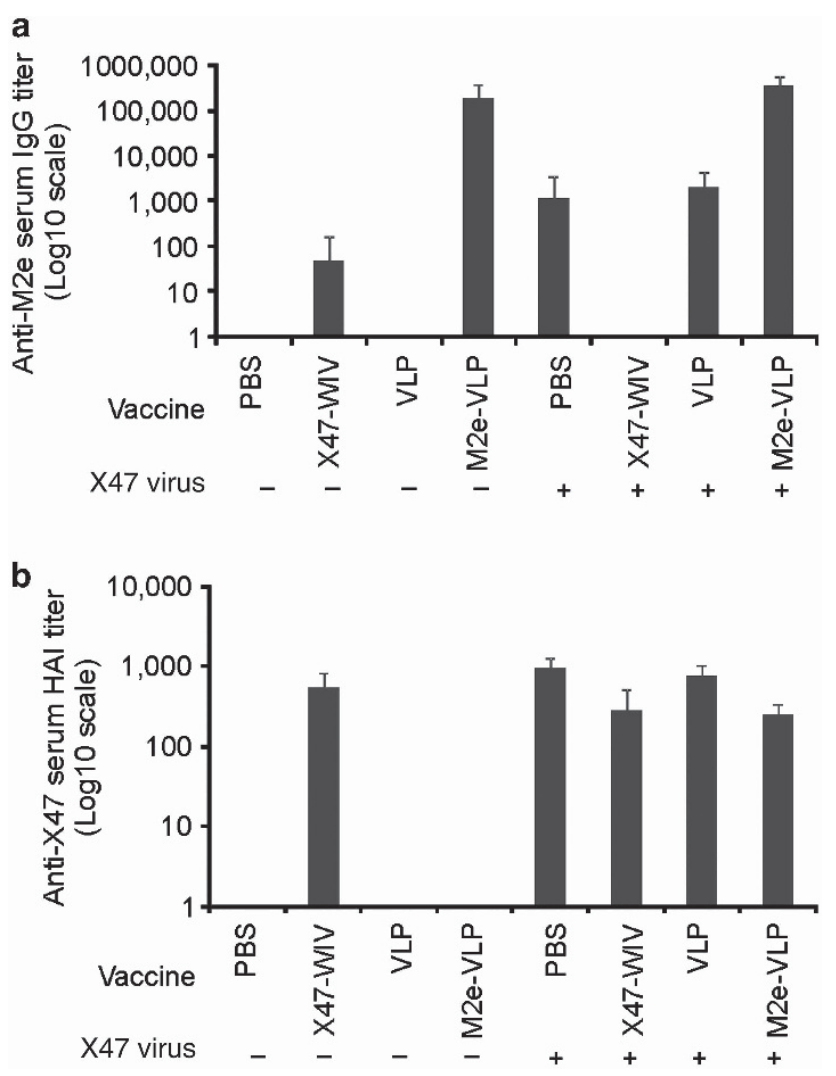

Figure 6 Comparison of extracellular domain of matrix 2 protein (M2e)-specific and hemagglutination inhibitory (HAI)-antibody titers after mock or X47 challenge. BALB/c mice were vaccinated and challenged as described on the $x$ axis, and serum was prepared from blood sampled on day 21 after mock or X47 challenge. (a) Endpoint M2e-specific serum immunoglobulin $\mathrm{G}$ ( $\mathrm{ggG}$ ) titers were determined by M2e peptide enzyme-linked immunosorbent assay. (b) HAl antibody titers in serum. HAI endpoint titers were determined using chicken red blood cells and 4 hemagglutinin units of $X 47$ virus. Bars represent averages ( $n=20$ per group) and error bars represent standard errors. PBS, phosphate-buffered saline; VLP, virus-like particles; WIV, whole inactivated virus.

Our experimental model system is based on immunization of immunologically naive hosts, resembling young children, many of which have not previously experienced influenza virus infection. ${ }^{25}$ The advantage of an M2e vaccine over a conventional influenza A vaccine was demonstrated with the use of incomplete Freund's adjuvant, an adjuvant that is not acceptable for human use. As an alternative, we also used alum adjuvanted M2e-VLPs that were administered intramuscularly. This resulted in a similar outcome although morbidity after primary challenge with $\mathrm{X} 47$ virus was more pronounced, presumably as a result of the low M2e-specific IgG2a titers that were induced with alum (see Supplementary Figure S7 online). It is possible to consider that exposure to influenza virus infection of the M2e-immune host represents a mucosal immunization strategy offered by nature. The combined immune response directed against $\mathrm{M} 2 \mathrm{e}$ vaccine and the tempered influenza virus infection results in cross-protective humoral (anti-M2e IgG) and cellular (e.g., NP-specific) immunity. By sharp contrast, the outcome of WIV-immune animals against heterosubtypic secondary challenge was even worse than that of the control animals.

Young infants who usually have not yet been exposed to influenza are being considered as an important target group for licensed influenza vaccines. ${ }^{11}$ This recommendation is rational, influenza vaccines are very safe, and the potential positive impact on public health of a policy to vaccinate against seasonal influenza starting from the age of 6 months is likely to be high. However, our results highlight and confirm a potential long-term protection problem associated with the use of inactivated influenza vaccines in influenza-naive recipients. ${ }^{9}$ It is likely that several years of such a vaccination policy will weaken influenza-specific cellular immunity in this target group. During a pandemic outbreak, these vaccinated individuals would be predicted to be much more vulnerable to infection by the new virus. Our data also propose an alternative influenza vaccine strategy targeted to young children that may overcome this problem.

Protection induced by vaccination with M2e-VLP allows limited virus replication and hence viral antigen production and presentation to the host immune system, while disease is strongly controlled. M2e-VLP vaccine used in our experiment mismatches on 4-5 positions with the "pandemic" challenge viruses. Nevertheless, immunization with M2e-VLPs alone provided protection against mortality after challenge with "pandemic" virus. Protection was enhanced when these M2e-immune mice had been previously exposed to "seasonal" virus. An alternative vaccination strategy that may induce cellular immunity against influenza is the use of live attenuated influenza vaccines. These vaccines also require annual updating and induce HAI titers, but on top of that also induce T-cell immunity. ${ }^{26}$ These vaccines are already licensed to children $>2$ years.

Most marketed influenza vaccines for human use are split vaccines containing purified fractions of HA and NA and, unlike WIV vaccine that we used, lack NP and M1. Nevertheless, NP155-specific T-cell activation was absent or very weak before or after homologous influenza virus challenge (Figure $\mathbf{5 c}$ and see Supplementary Figure S2c online). NP155-responsive $\mathrm{CD}^{+}$splenic T-cell fractions derived from challenged M2eimmune mice showed a more activated profile, as reflected by the higher percentages of IFN- $\gamma$-producing cells, which correlated with enhanced antigen-specific lytic activity (Figure 5c, and see Supplementary Figure S2c-e online). This suggests that the infection-permissive nature of M2e-based vaccines allows the induction of a more qualitative CTL response against internal viral gene products. In the mouse model, cross-reactive T-cell responses induced by previous infection with a seasonal $\mathrm{H} 3 \mathrm{~N} 2$ virus mediate protection against $\mathrm{pH} 1 \mathrm{~N} 1$ challenge. ${ }^{27}$ NP-reactive T-cell responses measured in vivo are also boosted upon re-encounter with heterologous virus in M2e-immune mice and to levels that are similar to those in rechallenged PBS or control VLP groups (Figure $\mathbf{9 b}$ and see Supplementary Figure S6b online). The size and relative epitope dominance of CD8 ${ }^{+} \mathrm{T}$-cell response can alter upon re-exposure to antigen, e.g., in a vaccination scheme with multiple injections or during 

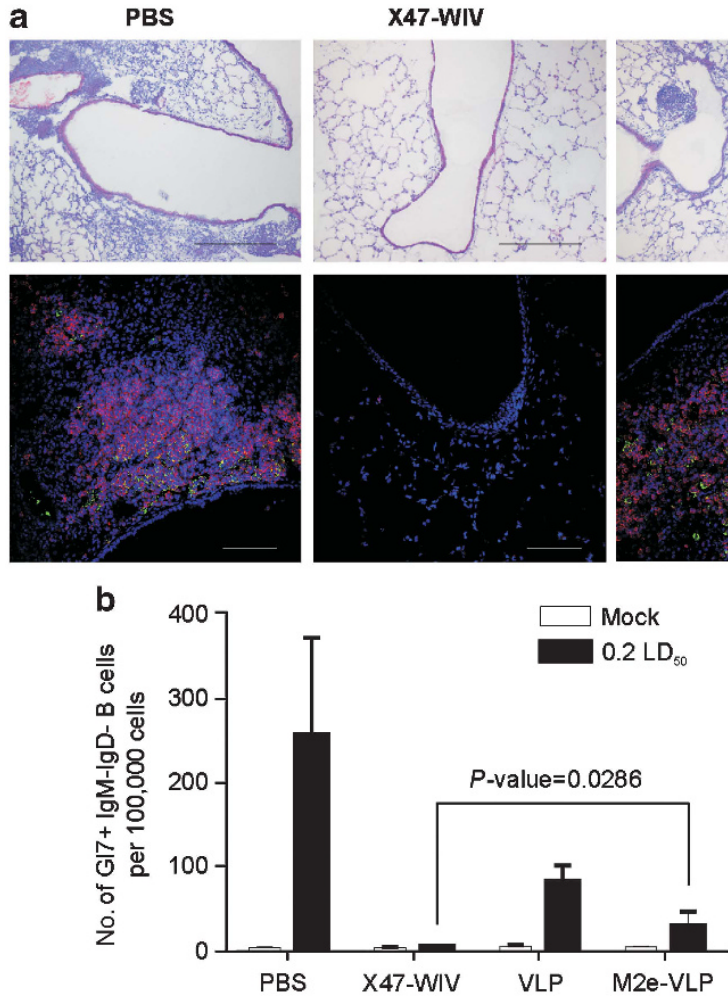

VLP
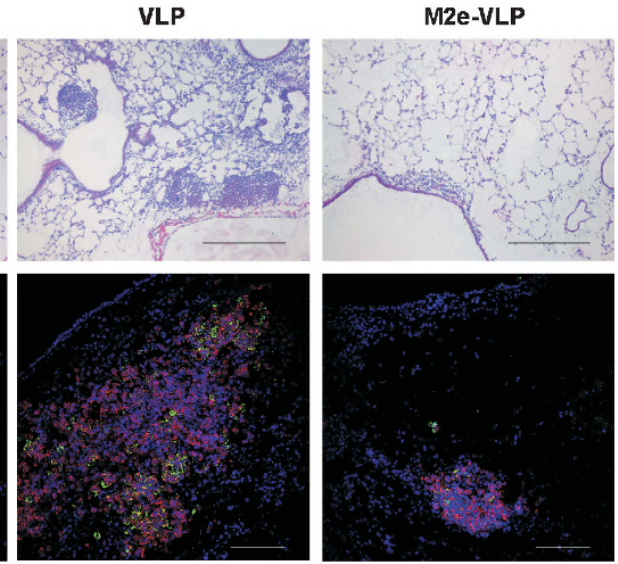

C

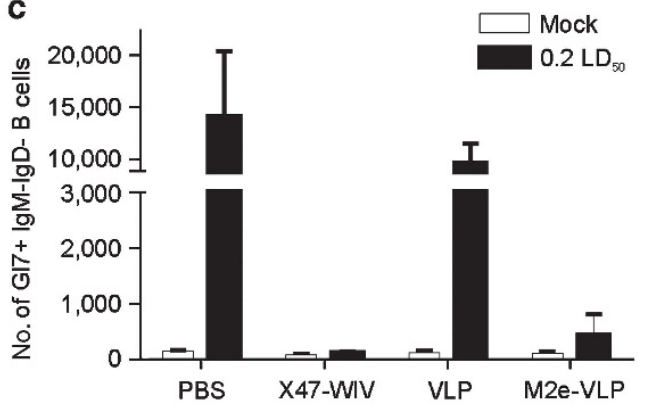

Figure 7 Inducible bronchus associated lymphoid tissue (BAAT) after sublethal X47-challenge. (a) Presence of iBALT was investigated by histological analysis of lung sections isolated 21 days after primary sublethal X 47 challenge. Lung sections were stained with hematoxylin for screening purposes (top row) and immunohistochemistry was used to confirm the presence of GL7+ B-cells (bottom row). (b and c) Formation of iBALT was evaluated by counting GL7+ immunoglobulin $\mathrm{M}(\mathrm{lgM})^{-} / \lg \mathrm{D}^{-}$B-cells by flow cytometry. Extracellular domain of matrix 2 protein (M2e)-VLP (virus-like particles)-vaccinated mice showed significantly more iBALT formation than in X47-WIV (whole inactivated virus)-vaccinated mice (two-sided Mann-Whitney $U$ test). Error bars represent standard error of the mean. DAPI, 4',6-diamidino-2-phenylindole; $L_{50}$, lethal dose, $50 \%$; PBS, phosphate-buffered saline.

reinfection. ${ }^{28,29}$ However, in our model using WIV or M2e-VLP the relative immunodominance hierarchy between the HA518and NP155-restricted T-cell responses were unaffected (see Supplementary Figure S2c,d online).

Patients that experienced an infection with 2009 pH1N1 virus can produce antibodies that are directed against conserved epitopes in HA. ${ }^{30}$ We found that M2e-based immunity allows the induction of neutralizing antibodies against the challenge virus, that are comparable with those induced in mice vaccinated with WIV before the "seasonal" challenge, and which correlated with full protection. However, in none of the experiments cross-reactive HAI-titers against the "pandemic" viruses were detected after the challenge with "seasonal" virus (data not shown). Our results corroborate the findings of Schulman and Kilbourne ${ }^{31}$ who reported in 1965 that contrary to respiratory infection with replicating virus, repeated parenteral injections of formalin-inactivated influenza virus fails to induce HSI, despite the induction of high antibody levels against the vaccination strain. They also noticed that production of HAI antibodies after infection was accelerated when mice were already primed by a previous heterologous infection, which they attributed to B-cell responses primed in proximity of the respiratory tract. We now know that respiratory infection with influenza virus induces BALT formation in mice. ${ }^{17}$ In infected naive mice, iBALT contributes to protection by de novo induction of virusspecific B- and T-cell responses. ${ }^{17,32-34}$ Formation of iBALT in M2e-immune mice after a sublethal infection with "seasonal" virus was higher (significant after X47 challenge) compared with WIV-vaccinated mice (Figure $7 \mathbf{b}$ and see Supplementary Figure S4b online).

It takes 6 months to produce and validate an HA-based influenza vaccine. ${ }^{35}$ Our approach could lead to development of a vaccine that is always available. Moreover, our vaccine provides not only universal antibody-based protective immunity but, as demonstrated here, also allows induction of T-cell immunity against conserved internal influenza proteins, much like a natural infection but with milder morbidity. Moreover, as viral antigen is produced each time the vaccinated individual is exposed to influenza $\mathrm{A}$ virus, the host immune responses to multiple (varying) epitopes is updated naturally. A trade-off for such an infection-permissive vaccine could be transient, but compared with unprotected subjects presumably milder, morbidity upon exposure to influenza virus. In the long run, implementation of this vaccination strategy is expected to provide broad-spectrum heterosubtypic protection in the human population. From both experimental and pediatric sides, concerns 

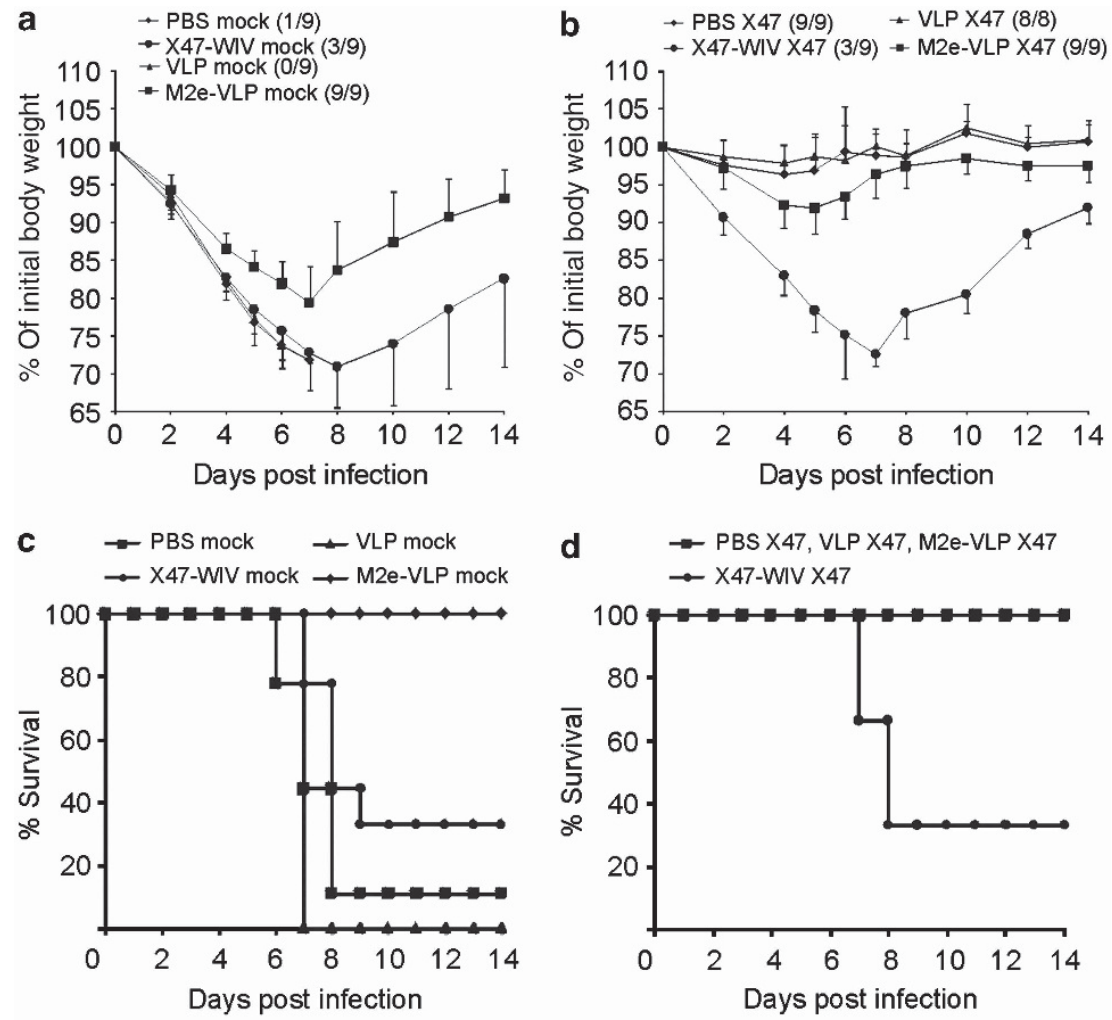

Figure 8 Morbidity and mortality after a potentially lethal pH1N1 infection. (a) Weight loss following primary pH1N1 (2 LD 50 (lethal dose, 50\%)) challenge, i.e., of mice immunized as indicated that had previously been mock-challenged. Survival is indicated between brackets. Extracellular domain of matrix 2 protein (M2e)-VLP (virus-like particles)-vaccinated mice show less morbidity than whole inactivated virus (WIV)-immune mice $\left(P<0.05\right.$ between 2 and 8 days post infection (dpi), two-sided Mann-Whitney $U$ test). (b) Weight loss following secondary $p H 1 N 1\left(2 L_{50}\right)$ challenge, i.e., of mice immunized as indicated that had previously been challenged with a sublethal dose of X47 virus. Survival is indicated between brackets. Morbidity was significantly higher in X47-WIV-immunized mice than in phosphate-buffered saline (PBS)-, VLP-, and M2e-VLP-immunized mice from 2 to 14 dpi (two-sided Mann-Whitney $U$ test, $P<0.05$ ). (c) Mice that received a mock challenge on the first occasion were protected from death upon pH1N1 infection only if they had been vaccinated with M2e-VLP. M2e-VLP-immunized mice were significantly better protected than PBS-, X47-WIV-, or VLP-immunized mice after lethal, primary challenge with pH1N1 (log-rank test, $P<0.01$ ). (d) Mortality rate after challenge with $2 \mathrm{LD}_{50}$ of $\mathrm{pH} 1 \mathrm{~N} 1$ virus in mice that had been pre-exposed to and recovered from a primary sublethal challenge with X47. Mice vaccinated with PBS, VLP, or M2e-VLP were significantly better protected than WIV mice (log-rank test, $P<0.01)$.

on vaccinating young children from 6 months on with classical inactivated vaccines, have been outed. ${ }^{9,36,37}$ As young infants are immunologically naive, they might not be allowed to build up a natural level of HSI when vaccinated too early and repeatedly with conventional influenza vaccines. These concerns are, to some extent, hypothetical because protection by inactivated influenza vaccines is likely not sterilizing in each individual and over an entire influenza season. In particular, in children, the HAI titer that correlates with protection is presumably much higher than the gold standard 1:40 value. ${ }^{38}$ Even though inactivated influenza vaccines may not induce sterilizing immunity in children, there is evidence that their use hampers the induction of cellular immunity. ${ }^{10}$ On the other hand, young children are at increased risk during influenza outbreaks and vaccinating them is cost-effective and life-saving. ${ }^{39,40}$ We believe that our universal vaccine might help overcome this problem as it may protect vaccinated individuals against multiple strains at all time by targeting M2e and meanwhile allowing the induction of HSI by natural infection.

\section{METHODS}

\section{Influenza viruses, mice and infections}

Influenza NC virus strain (H1N1) has been described ${ }^{41}$ and was recommended by the World Health Organization as the $\mathrm{H} 1 \mathrm{~N} 1$ vaccine component in conventional vaccines from 2000 to 2006. This H1N1 virus, here referred to as NC, was kindly provided by Dr Alan Hay (MRC National Institute for Medical Research, Mill Hill, London, UK) and adapted to mice by serial passages. A/swine/Ontario/42729A/01 (H3N3), kindly provided by Dr Suzan Carman (Guelph University, Ontario, Canada), has an avian-type M2e and was adapted to BALB/c mice by serial passages. The virus is lethal to naive mice even at low doses $\left(\mathrm{LD}_{50} / \mathrm{TCID}_{50}=2\right)$. We chose this virus as a pandemic virus in our model because this is a wholly avian virus that was isolated from pigs, suggesting that it can cross the species barrier. ${ }^{42}$ In addition, we could work with this virus in our BSL2 ${ }^{+}$(biosafety level 2)-contained laboratory. Influenza A/X47 virus strain $(\mathrm{H} 3 \mathrm{~N} 2)$ is a reassortant laboratory strain (A/Victoria/3/75 (H3N2) ×A/Puerto Rico/8/34 (H1N1)) and was adapted to mice. ${ }^{12} \mathrm{pH} 1 \mathrm{~N} 1$ (kindly provided by Dr Bernard Brochier, Scientific Institute of Public Health, Brussels, Belgium), is derived from a clinical isolate of the $\mathrm{pH} 1 \mathrm{~N} 1$ virus of 2009 and was adapted to mice by serial passages. Viruses were produced in MDCK (Madin-Darby canine kidney) cells in serum-free medium in the presence of TPCK 

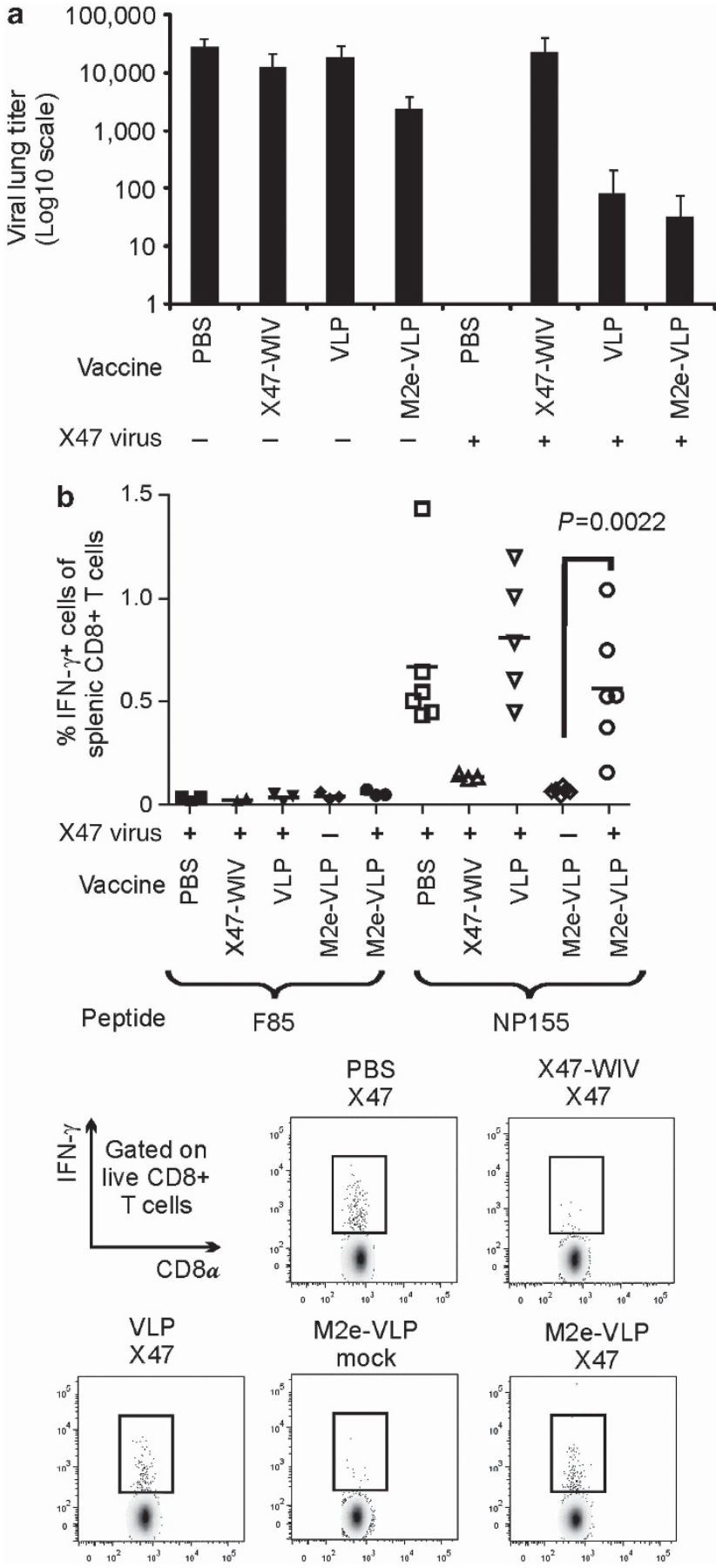

Figure 9 Viral lung titer and in vivo-restimulated T-cell responses after a potentially lethal challenge with $2 \mathrm{LD}_{50}$ (lethal dose, $50 \%$ ) of pandemic $\mathrm{H} 1 \mathrm{~N} 1$ ( $\mathrm{pH} 1 \mathrm{~N} 1$ ) virus. (a) Titers of $\mathrm{pH} 1 \mathrm{~N} 1$ virus in the lung isolated 6 days post infection. (b) Top: nucleoprotein (NP)-specific T-cell responses after pandemic $\mathrm{pH} 1 \mathrm{~N} 1$ challenge as determined by in vivo stimulation with NP155 peptide for $6 \mathrm{~h}$ before flow cytometric analysis of interferon (IFN)- $\gamma$-producing splenocytes. In vivo restimulation with F85 peptide was used as an irrelevant peptide control. "-" on $\mathrm{x}$ axis denotes previous mock challenge and "+" previous challenge with X47 virus. $(P=0.0022$, two-sided Mann-Whitney $U$ test, comparison between the mock- and X47-prechallenged groups). Bottom: representative plots for the flow cytometric analysis of IFN- $\gamma$-producing CD8 + T-cell responses. M2e, extracellular domain of matrix 2 protein; PBS, phosphate-buffered saline; VLP, virus-like particles; WIV, whole inactivated virus.
(L-1-tosylamide-2-phenylethyl chloromethyl ketone)-treated trypsin (Sigma-Aldrich, Saint-Louis, MO).

Female BALB/c mice aged 6-8 weeks were obtained from Harlan (Boxmeer, The Netherlands) and housed under specified pathogen-free conditions with food and water ad libitum. Challenge under mild isoflurane anesthesia was by intranasal administration of $50 \mu \mathrm{l}$ virus preparation diluted in PBS. Decrease in body weight was used as a measure of morbidity after infection. Mice that had lost $>30 \%$ of their initial body weight were killed. All infections were conducted under BSL- ${ }^{+}$containment and were authorized by the Institutional Ethics Committee on Experimental Animals.

\section{Vaccines and immunization}

WIV vaccine was produced as described. ${ }^{14}$ Briefly, mouse-adapted X47 or NC virus was grown on MDCK cells in serum-free medium in the presence of TPCK-treated trypsin. Seven days after inoculation, culture medium was collected and centrifuged twice for $10 \mathrm{~min}$ at $450 \mathrm{~g}$ to remove cellular debris. Virions were then pelleted by centrifugation $\left(20,000 \mathrm{~g}, 4^{\circ} \mathrm{C}, 16 \mathrm{~h}\right)$. Virus was inactivated by dissolving the pellets in $0.05 \%$ formaldehyde (prepared from formalin stock) in PBS followed by continuous shaking for 7 days at $4{ }^{\circ} \mathrm{C} .{ }^{8}$ Formalin-containing buffer was exchanged for PBS $>10,000$-fold (volume/volume) by sequential ultrafiltration with Vivaspin filtration columns (Sartorius Stedim Biotech, Aubagne Cedex, France) with $100 \mathrm{kDa}$ cutoff. X47-WIV was stored at $4{ }^{\circ} \mathrm{C}$ in the dark until used. Mice were primed and boosted with $15 \mu \mathrm{g}$ (total protein) of X47-WIV dissolved in $50 \mu \mathrm{l}$ of PBS and injected intramuscularly in the quadriceps under mild anesthesia. In all, $15 \mu \mathrm{g}$ WIV corresponds with 770 HA units for X47-WIV and 310 HA units for NC-WIV. The control group received $50 \mu \mathrm{PBS}$.

Unsubstituted VLP and VLP substituted with recombinant M2e substituted (M2e-VLP) were produced in Escherichia coli and have been described. ${ }^{14}$ In brief, unsubstituted VLPs are comprised of hepatitis B core antigen (amino-acid residues 1-149, followed by a cysteine residue). M2e-VLPs contain three tandem copies of M2e fused to the $\mathrm{N}$-terminus of hepatitis B core antigen. In the first and second copy of M2e cysteines at positions 17 and 19, respectively, were changed into serines whereas the third, carrier proximal, M2e copy retained these cysteines. Purity, antigenicity, and VLP assembly were assessed by sodium dodecyl sulfatepolyacrylamide gel electrophoresis, western blot analysis, and transmission electron microscopy, respectively (see Supplementary Figure S8 online). Each mouse was injected intraperitoneally with $10 \mu \mathrm{g}$ of either VLP, formulated with incomplete Freund's adjuvant or intramuscularly with alum adjuvant. Booster injections were given 3 weeks after priming. Three weeks after the second vaccination, mice were challenged with 0.2 $\mathrm{LD}_{50}$ of X47 virus or mock-challenged with PBS under mild isoflurane anesthesia. Four weeks later, when the mice had fully recovered, they were challenged with $2 \mathrm{LD}_{50}$ of $\mathrm{pH} 1 \mathrm{~N} 1$ virus. A complementary and entirely independent experiment was performed using NC-derived WIV, $\mathrm{PBS}, \mathrm{VLP}$, and M2e-VLP vaccine antigens but using a primary challenge with $0.1 \mathrm{LD}_{50}$ of $\mathrm{NC}$ virus or mock-challenge with PBS. Four weeks later, after full recovery of the mice from primary influenza virus exposure, animals were challenged with $2 \mathrm{LD}_{50}$ of mouse-adapted $\mathrm{H} 3 \mathrm{~N} 3$ virus in this second experiment.

\section{Serological analysis}

Blood was collected from the lateral tail vein before vaccination, 2 weeks after each vaccination, and 7 days before secondary challenge. Titers of total M2e-specific serum IgG were determined by enzyme-linked immunosorbent assay using 96-well Maxisorp immuno-plates (Nunc, Roskilde, Denmark) coated overnight with M2e peptide $\left(2 \mu \mathrm{g} / \mathrm{ml}^{-1}\right.$ in carbonate buffer, $50 \mu \mathrm{l}$ per well, $\left.37^{\circ} \mathrm{C}\right)$ or WIV $\left(2 \mu \mathrm{g} \mathrm{ml}^{-1}\right.$ in PBS, $100 \mu \mathrm{l}$ per well, $4^{\circ} \mathrm{C}$ ). After coating, plates were washed twice with PBS $+0.1 \%$ Tween 20 and blocked with $1 \%$ bovine serum albumin (Sigma-Aldrich) in PBS. The presence of M2e- or WIV-specific IgG in the serum was determined by incubating $1 / 3$ serial dilutions of mouse serum in the coated wells, starting with a $1 / 100$ dilution, for $1 \mathrm{~h}$. Sheep-derived anti-mouse serum conjugated with horseradish peroxidase (GE Healthcare UK, Chalfont 
St Giles, UK) and tetramethylbenzidine substrate (Sigma-Aldrich) were used to determine specific antibody titers. Antibody titers are defined as the reciprocal of the highest dilution with an $\mathrm{OD}_{450}$ that is at least two times the $\mathrm{OD}_{450}$ of a pool of pre-immune serum samples.

HAI activity was measured in twofold dilutions of pre-immune and immune sera according to the guidelines of the World Health Organization (WHO manual on animal influenza diagnosis and surveillance, 2002, Geneva; (WHO/CDS/CSR/NCS/2002.5 $)^{28-39}$ ). Briefly, sera were incubated at $56^{\circ} \mathrm{C}$ for $10 \mathrm{~min}$ to inactivate complement. Each volume of serum was treated with four volumes of receptor destroying enzyme (cholera filtrate from Vibrio cholerae culture fluid, SigmaAldrich) to remove nonspecific agglutinins. The sera were then incubated with 0.1 volumes of $50 \%$ chicken red blood cells (RBCs) in PBS. Treated serum samples were mixed with four hemagglutination units of X47 or $\mathrm{pH} 1 \mathrm{~N} 1$ virus in a final volume of $50 \mu \mathrm{l}$ to which antibodies were first allowed to bind for $1 \mathrm{~h}$ at room temperature. Equal volumes of a $0.5 \%$ $\mathrm{RBC}$ suspension were added and HAI titers were recorded 30 min later. Endpoint titers were defined as the dilutions at which hemagglutination was inhibited completely.

\section{Lung virus titers}

Three mice from each group were killed on day 6 after infection and lungs were removed aseptically and homogenized in $1 \mathrm{ml}$ PBS using a RZR 2020 homogenizer (Heidolph Instruments, Schwabach, Germany). The homogenates were diluted to $2 \mathrm{ml}$ and centrifuged ( $5 \mathrm{~min}, 400 \mathrm{~g}$ and $4^{\circ} \mathrm{C}$ ) to remove cellular debris before storage at $-80^{\circ} \mathrm{C}$. Titers of infectious virus were determined in triplicate by titration on MDCK cells in serum-free TPCK-treated trypsincontaining medium. Endpoint virus titers were determined by measuring chicken RBC agglutination activity in the cell supernatant 7 days after infection and using the calculation of Reed and Muench. ${ }^{43}$

\section{T-cell analysis}

IFN- $\gamma$ enzyme-linked immunospot assay. IFN- $\gamma$ enzyme-linked immunospot plates were from U-Cytech Biosciences (Utrecht, The Netherlands). T-cell analysis was performed according to the manufacturer's protocol. Briefly, 96-well immuno-plates were coated with sterile monoclonal anti-IFN- $\gamma$ antibodies and blocked with blocking buffer. On day 10 after infection, the spleens of six mice per group were isolated aseptically and splenocytes were prepared. After lysis of RBCs with $\mathrm{NH}_{4} \mathrm{Cl}$ solution, $3 \times 10^{5}$ splenocytes were plated in $100 \mu \mathrm{l}$ of culture medium supplemented with restimulation peptide at $5 \mu \mathrm{g} \mathrm{ml}^{-1}$. High-pressure liquid chromatography-purified peptides ( $>95 \%$ purity) were purchased from Pepscan (Lelystad, The Netherlands). The MHC-I (major histocompatibility complex I)-binding peptides were H2d-restricted NP-derived TYQRTRALV (NP155; conserved in the challenge viruses used here), HA-derived IYSTVASSL (HA518), and negative control RSV-F (respiratory syncytial virus (RSV) F)derived KYKNAVTEL (F85). The MHC-II-binding peptides were SLLTEVETPIRNEWGCRCNGSSD (M2e) and negative control ISQAVHAAHAEINEAGR (OVA323). After $6 \mathrm{~h}$ of peptide restimulation, plates were washed with enzyme-linked immunosorbent assay wash buffer and IFN- $\gamma$ trapped on the plates was detected by a biotinylated polyclonal anti-IFN- $\gamma$ antiserum. GABA-conjugated streptavidin resulted in the formation of black silver spots at places where immune cells secreted IFN- $\gamma$ during peptide-restimulation. The spots were counted using an inverted light microscope.

MHC pentamer staining, ICS, and flow cytometry after ex vivo restimulation. On day 10 after infection, spleens of six mice per group were isolated aseptically and splenocytes were prepared. After lysis of $\mathrm{RBCs}$ with $\mathrm{NH}_{4} \mathrm{Cl}$ solution, $10^{6}$ splenocytes were plated in $200 \mu \mathrm{l}$ of culture medium supplemented with restimulation peptide (described above) at a concentration of $5 \mu \mathrm{g} \mathrm{ml}^{-1}$. After $6 \mathrm{~h}$ of peptide restimulation, $1 \mu \mathrm{l}$ Golgiplug (brefeldin A, BD, Erembodegem, Belgium) was added to $1 \mathrm{ml}$ culture medium for measurement of cytokine production by ICS. The
Cytofix/Cytoperm kit (BD) was used according to the manufacturer's protocol. Briefly, cells were stained for the surface marker CD3e-PE (phycoerythrin), CD4-FITC (fluorescein isothiocyanate), or CD8 $\alpha$ FITC (all from BD), fixed with $2 \%$ paraformaldehyde, permeabilized with saponin, and stained for IFN- $\gamma(\mathrm{BD})$. Cells were then analyzed by using a FacsCalibur or LSR II flow cytometer (BD) with FlowJo (Treestar, Ashland, Orlando) or FACSDIVA software (BD).

To quantify T cells recognizing the NP155 and HA518 peptides in a MHC-I context by their T-cell receptor, we used PE-conjugated pentamers linked to these peptides (ProImmune, Oxford, UK). Pentamer solution $\left(15 \mu \mathrm{l}\right.$ of $\left.0.05 \mathrm{mg} \mathrm{ml}^{-1}\right)$ was added to $10^{6}$ cells during peptide restimulation. Afterwards, staining of intracellular IFN $-\gamma$ was performed as described above.

In vivo killing assay. NP155-peptide-specific in vivo killing capacity of CTLs was assessed by using a protocol adapted from Romano et al. ${ }^{44}$ Briefly, spleens from naive BALB/c mice were isolated, split in two groups, and pulsed either with NP155-peptide or with F85 peptide for $1 \mathrm{~h}$ at $37^{\circ} \mathrm{C}$. Peptide was added at $10 \mu \mathrm{g} \mathrm{ml}^{-1}$ culture medium, which consisted of RPMI 1640 with 10\% fetal calf serum. After incubation and washing with PBS, NP155-pulsed cells were labeled with $10 \mu \mathrm{M}$ carboxyfluorescein diacetate succinimidyl ester (CFSE, Invitrogen, Gent, Belgium). F85pulsed cells were labeled with $1 \mu \mathrm{M}$ CFSE in PBS for $15 \mathrm{~min}$ at $37^{\circ} \mathrm{C}$ in the dark. NP155-pulsed cells and F85-pulsed cells were mixed in a 1:1 ratio and adoptively transferred to six receiver mice from each group (three mice challenged with X47 or NC and three mock-challenged mice). After $18 \mathrm{~h}$, spleens from receiver mice were isolated and analyzed on a FACS Calibur flow cytometer using Cellquest software (BD). NP155specific killing was defined as the ratio of the number of NP155-pulsed splenocytes (high-concentration CFSE) to F85-pulsed splenocytes (low-concentration CFSE).

Intracellular cytokine staining after peptide-specific in vivo restimulation (in vivo ICS). NP155-peptide-reactive T cells were restimulated in vivo at least 6 weeks after secondary challenge. For in vivo restimulation, splenocytes were derived from a naive BALB/c mouse and pulsed with peptide as described for the in vivo killing assay. After pulsing, cells were washed with PBS and counted. Five million NP155-peptidepulsed congenic splenocytes were mixed with $250 \mu \mathrm{g}$ brefeldin A (SigmaAldrich) in $500 \mu \mathrm{l}$ PBS and adoptively transferred to receiver mice by intravenous (IV) injection. Six hours after injection of these stimulatory cells, spleens were removed and single-cell suspensions prepared. After lysis of RBCs with $\mathrm{NH}_{4} \mathrm{Cl}$ solution, surface markers and intracellular IFN- $\gamma$ were stained and analyzed as described for ICS above. Naive receiver mice or restimulator cells pulsed with the irrelevant F85-peptide were used as negative controls. This protocol is similar to the protocol described for the in vivo killing assay ${ }^{45}$ and to the protocol for in vivo ICS during viral infection described by Liu and Whitton, ${ }^{46}$ but to our knowledge, this is the first peptide-specific in vivo restimulation described for ICS so far.

Analysis of iBALT induction. For histology, lungs were inflated with a 1:1 mixture of PBS with Neg-50 cryo-medium (Prosan, Walldorf, Germany). Lungs were excised and snap frozen in liquid nitrogen before storage at $-80^{\circ} \mathrm{C}$. Cryosections of $5 \mu \mathrm{m}$ were made. First analysis for the presence of organized lymphoid tissue in lungs was performed on hematoxylin-stained sections using a light microscope (Zeiss, Oberkochen, Germany). More in-depth characterization of iBALT structures involved using confocal microscopy to visualize $\mathrm{B}$ cells and germinal center formation in lung slices stained for B220 (PE, BD) and GL7 (FITC, BD), respectively. Nuclei of cells in the cryosections were counterstained with 4',6-diamidino-2-phenylindole (Invitrogen). Pictures are representative of four mice per group.

Quantification of iBALT was performed with a three-laser LSR II flow cytometer (BD). Lungs were isolated, homogenized in PBS, and forced through a $40-\mu \mathrm{m}$ filter (Nunc) to obtain single-cell suspensions. 
Nonspecific staining of immune cells was prevented by using FcBlock (BD). Cells were stained with mAbs against B220 (PE-Cy7, BD), IgM (PerCP-Cy5.5), IgD (PE, BD), and GL7 (FITC, BD). Staining with an Aqua Live/Dead marker (Invitrogen) allowed exclusion of dead cells from the analysis. The degree of iBALT induction was defined as the number of $\mathrm{B}$ cells in the live gate that were negative for IgM and IgD double but positive for GL7.

\section{Statistical analyses}

Statistical analyses were performed with Graphpad Prism version 4.00 for Windows (GraphPad Software, San Diego California; www. graphpad.com) and with the R language and environment for statistical computing, R Development Core Team, 2009 (R Foundation for Statistical Computing, Vienna, Austria (ISBN 3-900051-07-0, URL http://www. R-project.org). The statistical tests used for computing significance levels are mentioned in the text. Significance levels are mentioned in the text or indicated with single asterisk $(P<0.05)$ or double asterisks $(P<0.01)$ in figures when not mentioned in the text.

SUPPLEMENTARY MATERIAL is linked to the online version of the paper at http://www.nature.com/mi

\section{ACKNOWLEDGMENTS}

We thank Anouk Smet and Frederik Vervalle for excellent technical assistance, Dr Amin Bredan for editing the manuscript and Riet Derycke and Jan Mast (EM-unit, CODA-CERVA, Brussels, Belgium) for making the transmission electron micrographs. We are grateful to Dr Alan Hay (MRC National Institute for Medical Research, Mill Hill, London, UK), Dr Suzan Carman (University of Guelph, Guelph, Ontario, CA), and Dr Bernard Brochier (Scientific Institute of Public Health, Brussels, Belgium) for providing influenza virus strains. M.S. was a beneficiary of a "Bijzonder Onderzoeksfonds" research grant from Ghent University. L.I.I was a beneficiary of the Belgian Federal Sciences Administration (Federale Wetenschapsbeleid, BELSPO) and was supported by Ghent University IOFgrant Stepstone IOF08/STEP/001. Research related to M2e-based influenza vaccines in the group of XS is supported by FWO grant 3G037510, Ghent University IOF-grant Stepstone IOF08/STEP/001, and research collaboration with Sanofi Pasteur. The Flow Cytometer core facility at DMBR is supported by a Methusalem grant (BOF09/01M00709) from Ghent University.

\section{DISCLOSURE}

Walter Fiers, one of the co-authors holds patent rights on the use of $\mathrm{M} 2 \mathrm{e}-$ based influenza vaccines. Part of the research on M2e-immunity in the group of Xavier Saelens (Ghent University and VIB) is supported by a research collaboration with Sanofi Pasteur.

(C) 2013 Society for Mucosal Immunology

\section{REFERENCES}

1. Bodewes, R. et al. Vaccination against human influenza $A / H 3 N 2$ virus prevents the induction of heterosubtypic immunity against lethal infection with avian influenza A/H5N1 virus. PLoS One 4, e5538 (2009).

2. Brammer, L., Budd, A. \& Cox, N. Seasonal and pandemic influenza surveillance considerations for constructing multicomponent systems. Influenza Other Respir. Viruses 3, 51-58 (2009).

3. Neumann, G., Noda, T. \& Kawaoka, Y. Emergence and pandemic potential of swine-origin $\mathrm{H} 1 \mathrm{~N} 1$ influenza virus. Nature 459, 931-939 (2009).

4. Gotch, F., McMichael, A., Smith, G. \& Moss, B. Identification of viral molecules recognized by influenza-specific human cytotoxic T lymphocytes. J. Exp. Med. 165, 408-416 (1987).

5. Moskophidis, D. \& Kioussis, D. Contribution of virus-specific CD8+ cytotoxic T cells to virus clearance or pathologic manifestations of influenza virus infection in a T cell receptor transgenic mouse model. J. Exp. Med. 188, 223-232 (1998).

6. Topham, D.J., Tripp, R.A. \& Doherty, P.C. CD8+ T cells clear influenza virus by perforin or Fas-dependent processes. J. Immunol. 159, 5197-5200 (1997).
7. Bodewes, R. et al. Vaccination against seasonal influenza $A / H 3 N 2$ virus reduces the induction of heterosubtypic immunity against influenza A/H5N1 virus infection in ferrets. J. Virol. 85, 2695-2702 (2011).

8. Bodewes, R. et al. Vaccination with whole inactivated virus vaccine affects the induction of heterosubtypic immunity against influenza virus $\mathrm{A} / \mathrm{H} 5 \mathrm{~N} 1$ and immunodominance of virus-specific CD8+ T-cell responses in mice. J. Gen. Virol. 91, 1743-1753 (2010).

9. Bodewes, R., Kreijtz, J.H. \& Rimmelzwaan, G.F. Yearly influenza vaccinations: a double-edged sword? Lancet Infect. Dis. 9, 784-788 (2009).

10. Bodewes, R. et al. Annual vaccination against influenza virus hampers development of virus-specific CD8 T cell immunity in children. J. Virol. 85, 11995-12000 (2011).

11. Fiore, A.E. et al. Prevention and control of influenza: recommendations of the Advisory Committee on Immunization Practices (ACIP), 2008. MMWR Recomm. Rep. 57, 1-60 (2008).

12. Neirynck, S. et al. A universal influenza A vaccine based on the extracellular domain of the M2 protein. Nat. Med. 5, 1157-1163 (1999).

13. Schotsaert, M., De Filette, M., Fiers, W. \& Saelens, X. Universal M2 ectodomain-based influenza A vaccines: preclinical and clinical developments. Expert Rev. Vaccines 8, 499-508 (2009).

14. De Filette, M. et al. Universal influenza A vaccine: optimization of M2-based constructs. Virology 337, 149-161 (2005).

15. Chen, W., Anton, L.C., Bennink, J.R. \& Yewdell, J.W. Dissecting the multifactorial causes of immunodominance in class I-restricted T cell responses to viruses. Immunity 12, 83-93 (2000).

16. Feng, J. et al. Influenza A virus infection engenders a poor antibody response against the ectodomain of matrix protein 2. Virol. J. 3, 102 (2006).

17. Moyron-Quiroz, J.E. et al. Role of inducible bronchus associated lymphoid tissue (iBALT) in respiratory immunity. Nat. Med. 10, 927-934 (2004).

18. Kreijtz, J.H. et al. Infection of mice with a human influenza A/H3N2 virus induces protective immunity against lethal infection with influenza $\mathrm{A} / \mathrm{H} 5 \mathrm{~N} 1$ virus. Vaccine 27, 4983-4989 (2009).

19. El Bakkouri, K. et al. Universal vaccine based on ectodomain of matrix protein 2 of influenza A: Fc receptors and alveolar macrophages mediate protection. J. Immunol. 186, 1022-1031 (2011).

20. Roose, K., Fiers, W. \& Saelens, X. Pandemic preparedness: toward a universal influenza vaccine. Drug News Perspect. 22, 80-92 (2009).

21. Song, J.M. et al. Influenza virus-like particles containing M2 induce broadly cross protective immunity. PLoS One 6, e14538 (2011).

22. Jegerlehner, A., Schmitz, N., Storni, T. \& Bachmann, M.F. Influenza A vaccine based on the extracellular domain of $\mathrm{M} 2$ : weak protection mediated via antibody-dependent NK cell activity. J. Immunol. 172, 5598-5605 (2004).

23. Song, J.M., Van Rooijen, N., Bozja, J., Compans, R.W. \& Kang, S.M. Vaccination inducing broad and improved cross protection against multiple subtypes of influenza A virus. Proc. Natl. Acad. Sci. USA 108, 757-761 (2011).

24. Ernst, W.A. et al. Protection against $\mathrm{H1}, \mathrm{H} 5, \mathrm{H} 6$ and $\mathrm{H} 9$ influenza $\mathrm{A}$ infection with liposomal matrix 2 epitope vaccines. Vaccine $\mathbf{2 4}$, 5158-5168 (2006).

25. Bodewes, R. et al. Prevalence of antibodies against seasonal influenza A and B viruses in children in Netherlands. Clin. Vaccine Immunol. 18, 469-476 (2011).

26. Hoft, D.F. et al. Live and inactivated influenza vaccines induce similar humoral responses, but only live vaccines induce diverse T-cell responses in young children. J. Infect. Dis. 204, 845-853 (2011).

27. Hillaire, M.L. et al. Cross-protective immunity against influenza pH1N1 2009 viruses induced by seasonal influenza A (H3N2) virus is mediated by virus-specific T-cells. J. Gen. Virol. 92, 2339-2349 (2011).

28. Belz, G.T., Xie, W., Altman, J.D. \& Doherty, P.C. A previously unrecognized $\mathrm{H}-2 \mathrm{D}(\mathrm{b})$-restricted peptide prominent in the primary influenza A virusspecific CD8(+) T-cell response is much less apparent following secondary challenge. J. Virol. 74, 3486-3493 (2000).

29. Rodriguez, F., Harkins, S., Slifka, M.K. \& Whitton, J.L. Immunodominance in virus-induced CD8(+) T-cell responses is dramatically modified by DNA immunization and is regulated by gamma interferon. J. Virol. 76, 4251-4259 (2002).

30. Wrammert, J. et al. Broadly cross-reactive antibodies dominate the human $\mathrm{B}$ cell response against 2009 pandemic $\mathrm{H} 1 \mathrm{~N} 1$ influenza virus infection. J. Exp. Med. 208, 181-193 (2011). 
31. Schulman, J.L. \& Kilbourne, E.D. Induction of partial specific heterotypic immunity in mice by a single infection with influenza a virus. J. Bacteriol. 89, 170-174 (1965).

32. GeurtsvanKessel, C.H. et al. Dendritic cells are crucial for maintenance of tertiary lymphoid structures in the lung of influenza virus-infected mice. J. Exp. Med. 206, 2339-2349 (2009).

33. Halle, S. et al. Induced bronchus-associated lymphoid tissue serves as a general priming site for $T$ cells and is maintained by dendritic cells. J. Exp. Med. 206, 2593-2601 (2009).

34. Moyron-Quiroz, J.E. et al. Persistence and responsiveness of immunologic memory in the absence of secondary lymphoid organs. Immunity 25, 643-654 (2006).

35. Stohr, K. Vaccinate before the next pandemic? Nature 465, 161 (2010).

36. Carrat, F., Lavenu, A., Cauchemez, S. \& Deleger, S. Repeated influenza vaccination of healthy children and adults: borrow now, pay later? Epidemiol. Infect. 134, 63-70 (2006).

37. Corbeel, L. Should healthy children be vaccinated against influenza? Comments about this query. Eur. J. Pediatr. 166, 629-631 (2007).

38. Hobson, D., Curry, R.L., Beare, A.S. \& Ward-Gardner, A. The role of serum haemagglutination-inhibiting antibody in protection against challenge infection with influenza A2 and B viruses. J. Hyg. (Lond) 70, 767-777 (1972).
39. Bhat, N. et al. Influenza-associated deaths among children in the United States, 2003-2004. N. Engl. J. Med. 353, 2559-2567 (2005).

40. Esposito, S. \& Principi, N. The rational use of influenza vaccines in healthy children and children with underlying conditions. Curr. Opin. Infect. Dis. 22, 244-249 (2009).

41. Daum, L.T. et al. Genetic and antigenic analysis of the first A/New Caledonia/20/99-like H1N1 influenza isolates reported in the Americas. Emerg. Infect. Dis. 8, 408-412 (2002).

42. Karasin, A.I., West, K., Carman, S. \& Olsen, C.W. Characterization of avian $\mathrm{H} 3 \mathrm{~N} 3$ and $\mathrm{H} 1 \mathrm{~N} 1$ influenza A viruses isolated from pigs in Canada. J. Clin. Microbiol. 42, 4349-4354 (2004).

43. Reed, L.J. \& Muench, H. A simple method of estimating fifty per cent endpoints. Am. J. Epidemiol. 27, 493-497 (1938).

44. Romano, M. et al. Induction of in vivo functional Db-restricted cytolytic T cell activity against a putative phosphate transport receptor of Mycobacterium tuberculosis. J. Immunol. 172, 6913-6921 (2004).

45. Barber, D.L., Wherry, E.J. \& Ahmed, R. Cutting edge: rapid in vivo killing by memory CD8 T cells. J. Immunol. 171, 27-31 (2003).

46. Liu, F. \& Whitton, J.L. Cutting edge: re-evaluating the in vivo cytokine responses of $C D 8+T$ cells during primary and secondary viral infections. J. Immunol. 174, 5936-5940 (2005). 